\title{
Crystallization of amorphous silicon by self-propagation of nanoengineered thermites
}

\author{
Maruf Hossain and Senthil Subramanian \\ Department of Electrical and Computer Engineering, University of Missouri, Columbia, Missouri 65211 \\ Shantanu Bhattacharya \\ Department of Biological Engineering, University of Missouri, Columbia, Missouri 65211 \\ Yuanfang Gao, Steve Apperson, and Rajesh Shende \\ Department of Electrical and Computer Engineering, University of Missouri, Columbia, Missouri 65211 \\ Suchi Guha, Mohammad Arif, and Mengjun Bai \\ Department of Physics, University of Missouri, Columbia, Missouri 65211 \\ Keshab Gangopadhyay and Shubhra Gangopadhyay
Department of Electrical and Computer Engineering, University of Missouri, Columbia, Missouri 65211
}

(Received 20 December 2006; accepted 29 December 2006; published online 7 March 2007)

\begin{abstract}
Crystallization of amorphous silicon $(a-\mathrm{Si})$ thin film occurred by the self-propagation of copper oxide/aluminum thermite nanocomposites. Amorphous $\mathrm{Si}$ films were prepared on glass at a temperature of $250{ }^{\circ} \mathrm{C}$ by plasma enhanced chemical vapor deposition. The platinum heater was patterned on the edge of the substrate and the $\mathrm{CuO} / \mathrm{Al}$ nanoengineered thermite was spin coated on the substrate that connects the heater and the $a$-Si film. A voltage source was used to ignite the thermites followed by a piranha solution $\left(4: 1\right.$ of $\left.\mathrm{H}_{2} \mathrm{SO}_{4}: \mathrm{H}_{2} \mathrm{O}_{2}\right)$ etch for the removal of residual products of thermite reaction. Raman spectroscopy was used to confirm the crystallization of a-Si. (C) 2007 American Institute of Physics. [DOI: 10.1063/1.2450672]
\end{abstract}

Polycrystalline silicon (poly-Si) is one of the most promising materials for fabricating solar cells and thin film transistors. It can be deposited directly by low pressure chemical vapor deposition or it can be prepared by various crystallization techniques of amorphous $\mathrm{Si}(a-\mathrm{Si}){ }^{1-4}$ Some of the current strategies include laser crystallization, ${ }^{2}$ hydrogen induced crystallization, ${ }^{3}$ and metal induced crystallization. ${ }^{4}$ Unlike most other techniques, laser induced crystallization does not require high temperatures $\left(>180^{\circ} \mathrm{C}\right)$ and long processing times to produce good quality poly-Si films. The major disadvantage of laser crystallization is its low throughput due to small laser spot size, which is not suitable for large area such as solar cells. Thus, high temperature and long processing times for various crystallization methods, and small spot size of the laser are not suitable for producing poly-Si film on a large surface area of glass or flexible plastic substrates. Low cost plastic substrates such as polyethersulphone can be used for flexible electronics if the device is fabricated under $180{ }^{\circ} \mathrm{C}$.

This study investigates the crystallization of $a$-Si layer achieved by the ignition of nanoengineered thermite materials such as $\mathrm{CuO} / \mathrm{Al}$. Explosives have been utilized previously to crystallize amorphous materials, ${ }^{5,6}$ however, there is no information currently available on thin film crystallization using nanoengineered thermites. Our approach utilizes thermite reaction to induce crystallization of $a$-Si thin film; such energetic reactions are self-propagating exothermic reactions, which produce localized heating effects. We discov-

\footnotetext{
${ }^{\text {a) }}$ Author to whom correspondence should be addressed; electronic mail: gangopaghyays@missouri.edu
}

ered that thermites, nanoengineered by the self-assembly approach, produced a self-propagating chemical reaction over a period of microseconds. ${ }^{7,8}$ The exothermic reaction propagates at a rate of $1500-2000 \mathrm{~m} / \mathrm{s}$ resulting in heat release. This heat can be used advantageously to crystallize $a$-Si. High quality poly-Si films can be prepared on large substrates utilizing this released heat.

Nanoengineered thermites were prepared by sonicating a mixture of $\mathrm{CuO}$ nanorods (10 $\mathrm{nm}$ diameter and $70 \mathrm{~nm}$ long) and aluminum nanopowder ( $80 \mathrm{~nm}$ diameter). The details of the nanorod preparation and the characterization of the thermites are presented in Ref. 9. The thermites displayed the following chemical reaction:

$$
3 \mathrm{CuO}+2 \mathrm{Al} \rightarrow 3 \mathrm{Cu}+\mathrm{Al}_{2} \mathrm{O}_{3}+\Delta H,
$$

where $\Delta H$ is the released heat. For $\mathrm{CuO} / \mathrm{Al}$ exothermic reaction, the released heat is $604 \mathrm{~kJ} / \mathrm{mol}$ and the adiabatic reaction temperature is $3794 \mathrm{~K} .{ }^{10}$

The $a$-Si samples were prepared by plasma enhanced chemical vapor deposition on glass substrates. The thickness of the $a$-Si layer was $300 \mathrm{~nm}$. A thin layer of platinum (90 $\mathrm{nm}$ thick and $2.5 \mathrm{~mm}$ wide) was deposited on the edge of the substrates, which functioned as a heater for initiating the self-propagating reaction for the energetic materials. The substrates with $a$-Si and the platinum heater were spin coated with the thermites and dried at $105^{\circ} \mathrm{C}$ in an oven for $10 \mathrm{~min}$. The scanning electron microscopy (SEM) cross sectional image of the $\mathrm{CuO} / \mathrm{Al}$ slurry used as the nanoengineered thermite in this experiment is shown in Fig. 1 The figure shows the presence of microvoids in $\mathrm{CuO} / \mathrm{Al}$ slurry coated films with scattered spots in contact with the sub- 


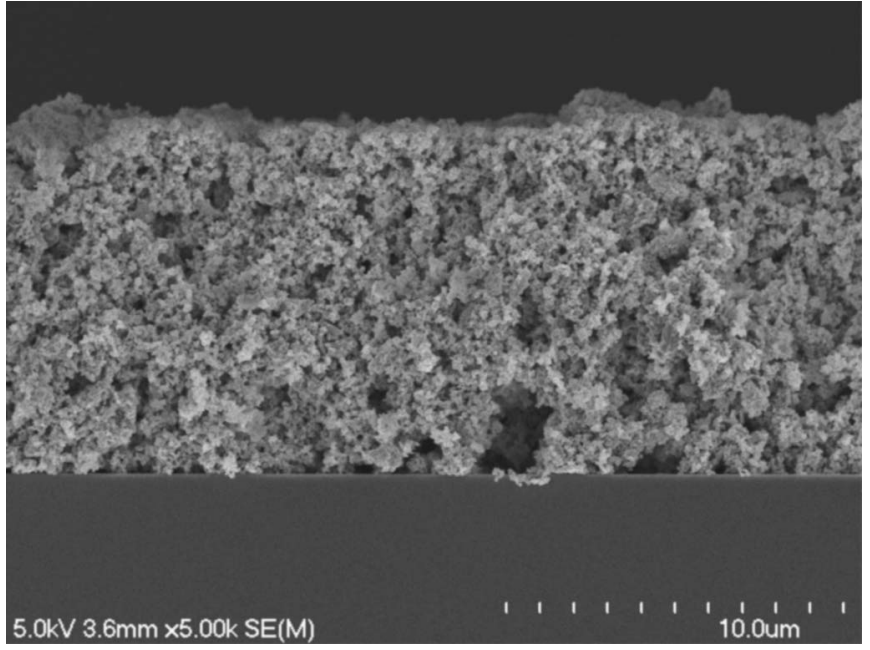

FIG. 1. SEM cross section image (scale: $10 \mu \mathrm{m}$ ) of $\mathrm{CuO}$ nanorod/Al nanoparticle slurry coating on Si substrate showing microvoid formation.

strate. The microlevel porosity, primarily due to poor particle film packing, may cause nonuniform heat release. After the ignition, the combustion products were rinsed first in acetone and then etched in a piranha solution $\left(4: 1\right.$ of $\left.\mathrm{H}_{2} \mathrm{SO}_{4}: \mathrm{H}_{2} \mathrm{O}_{2}\right)$. Samples were also made where multilayer $\mathrm{Pt} / \mathrm{Al}$ (four platinum layers $50 \mathrm{~nm}$ thick each and three Al layers $70 \mathrm{~nm}$ thick each) films were introduced between the $a$-Si films and the nanoengineered thermites. The goal of this experiment was to transfer heat from the $\mathrm{CuO} / \mathrm{Al}$ thermite to the $\mathrm{Pt} / \mathrm{Al}$ multilayer thermite films for initiating the self-propagation of this intermetallic system. As the $\mathrm{Pt} / \mathrm{Al}$ multilayer structure was a sputtered continuous thin film, it was expected that the heat release would be uniform. For the $\mathrm{Pt} / \mathrm{Al}$ exothermic reaction, the released heat is $280 \mathrm{~kJ} / \mathrm{mol}$ and the adiabatic reaction temperature is $3073 \mathrm{~K}^{10}$

The Raman spectra were measured at room temperature in a confocal geometry using a $785 \mathrm{~nm}$ diode laser. The power of the laser was low $(5 \mathrm{~mW})$ to avoid laser induced crystallization and the spot size was $3.5 \times 3.5 \mu \mathrm{m}^{2}$. SEM and
TABLE I. Fitted data for the samples prepared by the self-propagation of $\mathrm{CuO} / \mathrm{Al}$.

\begin{tabular}{clcc}
\hline \hline $\begin{array}{c}\text { Peaks } \\
\text { (standard) }\left(\mathrm{cm}^{-1}\right)\end{array}$ & Mode & $\begin{array}{c}\text { FWHM } \\
\left(\mathrm{cm}^{-1}\right)\end{array}$ & $\begin{array}{c}\text { Peak position } \\
\text { from the fit }\left(\mathrm{cm}^{-1}\right)\end{array}$ \\
\hline 520 & TO C-Si & 5 & 517 \\
$505-515$ & Grain boundary & 14 & 515 \\
480 & TO $a-\mathrm{Si}$ & 66 & 481 \\
\hline \hline
\end{tabular}

energy dispersive spectroscopy (EDS) were used to characterize the samples at atomic level. Atomic force microscopy (AFM) was used for surface morphology and grain size measurement.

The optical micrograph of the sample after piranha etching is shown in Fig. 2 along with the Raman spectra. The micrograph shows different regions in black and gray. The Raman mapping was performed on the sample on a 49 $\times 31.5 \mu \mathrm{m}^{2}$ area. The Raman spectra were measured in $2.5 \mu \mathrm{m}$ intervals. Each region was fitted with the single $\mathrm{Si}$ crystalline peak and the intensity of this peak is plotted as a function of the sample area in a color code on the optical micrograph where the intensity is lowest for the dark squares. Thus the dark regions (gray in the optical image) correspond to regions of almost no crystallization. The top spectrum of the figure shows that the film remains amorphous with a broad peak at $480 \mathrm{~cm}^{-1}$. This peak is due to the transverse optical mode of $a$-Si. ${ }^{11}$ The bottom spectrum of the figure shows that the $a$-Si partially crystallized with a sharp peak at $517 \mathrm{~cm}^{-1}$ and a broad amorphous peak around $480 \mathrm{~cm}^{-1}$. The middle spectrum shows only one sharp peak at $519 \mathrm{~cm}^{-1}$ without having an amorphous peak confirming complete crystallization in that region.

The data of the bottom spectrum in Fig. 2 are fitted with PEAKFIT software with one Lorentzian profile for the crystalline region and two Gaussian profiles for the grain boundary and amorphous regions. The data from the fit are summarized in Table I. The Raman peak from the crystalline component softens to $517 \mathrm{~cm}^{-1}$. This shift from the peak position

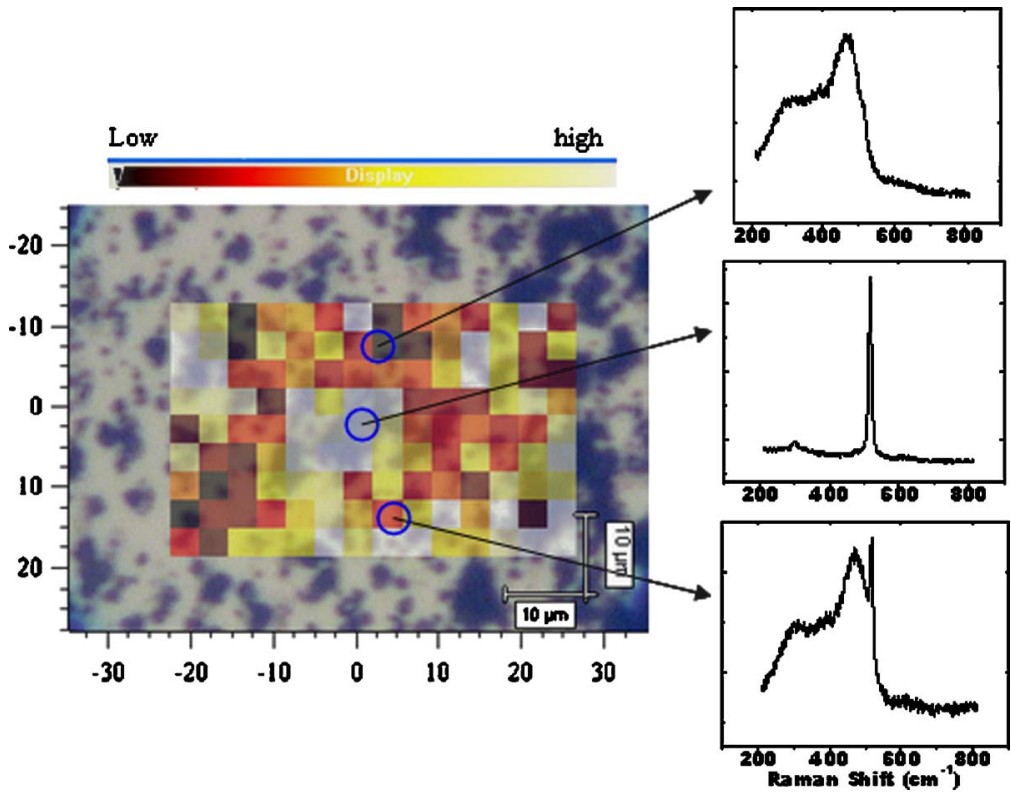

FIG. 2. Raman mapping of the samples prepared by the self-propagation of nanoengineered thermites. 


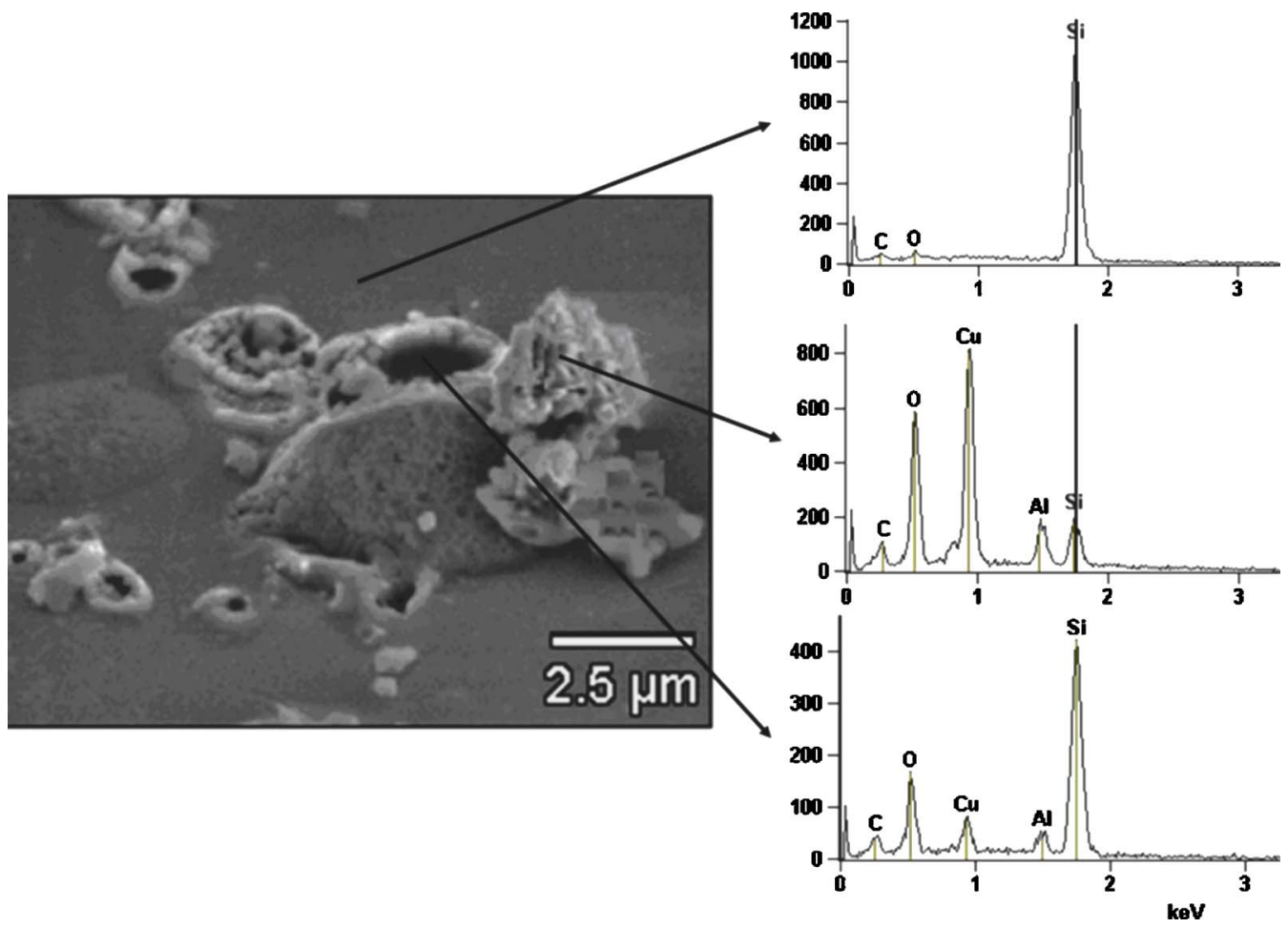

FIG. 3. Electron dispersive spectroscopy of the samples in a region where maximum crystallization was achieved.

of single crystalline $\mathrm{Si}$ (at $520 \mathrm{~cm}^{-1}$ ) usually occurs due to nanometer $(<10 \mathrm{~nm})$ size grains or due to residual stress. ${ }^{12}$ Kitahara et al. ${ }^{12}$ reported that peak shift due to smaller grain size occurs if full width at half maximum (FWHM) broadened over $8 \mathrm{~cm}^{-1}$. On the other hand, peak shift occurs due to stress with FWHM $<8 \mathrm{~cm}^{-1}$ as the grain size effect is negligible. Since FWHM for the crystallized region is $5 \mathrm{~cm}^{-1}$, which is close to the value obtained for single crystal silicon $\left(4 \mathrm{~cm}^{-1}\right)$, we believe that this shift is caused by the residual stress produced by the localized heating of the film. Crystalline volume fraction $X_{c}$ for this region is estimated to be $33 \%$ from $X_{c}=\left(I_{c}+I_{\mathrm{gb}}\right) /\left(I_{c}+I_{\mathrm{gb}}+I_{a}\right)$, where $I_{c}, I_{\mathrm{gb}}$, and $I_{a}$ are the areas under the peaks of crystalline, grain boundary, and amorphous peaks, respectively. ${ }^{11}$

The data of the middle spectrum of the figure (black region) were also fitted showing only one peak at $519 \mathrm{~cm}^{-1}$ with a FWHM of $6 \mathrm{~cm}^{-1}$. This region (black) did not show any amorphous peak indicating a crystalline volume fraction of $100 \%$. The difference in the peak position and crystalline volume fraction suggests that the region where thermites were in direct contact with $a$-Si crystallized maximally having lower residual stress since the peak shift is only one (from 520 to $519 \mathrm{~cm}^{-1}$ ). The region where thermites were not in direct contact with $a$-Si crystallizes less having higher residual stress since the peak shift is three (from 520 to $517 \mathrm{~cm}^{-1}$ ). The difference in the residual stress in two different regions may be due to the difference in the heat transfer process from the thermite reaction. Further experiments are needed to understand the effect of heat transfer rate on crystallization and thermal stress.

SEM and EDS were used to analyze the sample after the energetic reaction where maximum crystallization was achieved. The SEM image of Fig. 3 shows some peaks and valleys and a uniform flat region where EDS analysis was performed. The valleys or the peaks are formed where the thermite touches the $a$-Si, the region with no contact of thermite, and where the $a$-Si remained flat. Thus, during selfpropagation, the thermites reacted with $a$-Si at regions of contacts and in the other region, $a$-Si remained unreacted. The EDS analysis shown in Fig. 3 confirms the presence of $\mathrm{Cu}, \mathrm{Al}, \mathrm{Si}$, and $\mathrm{O}_{2}$ on the peaks. This indicates that $\mathrm{Cu}$ and $\mathrm{Al}_{2} \mathrm{O}_{3}$ produced during the exothermic thermite reaction also reacted with the $\mathrm{Si}$ film. The EDS on valleys shows $\mathrm{Cu}$ and $\mathrm{O}_{2}$, confirming that the reaction occurred in those regions, and $\mathrm{Si}$ was etched or pealed from the region. The EDS on the flat area did not show any $\mathrm{Cu}$ or $\mathrm{Al}$, which confirms that

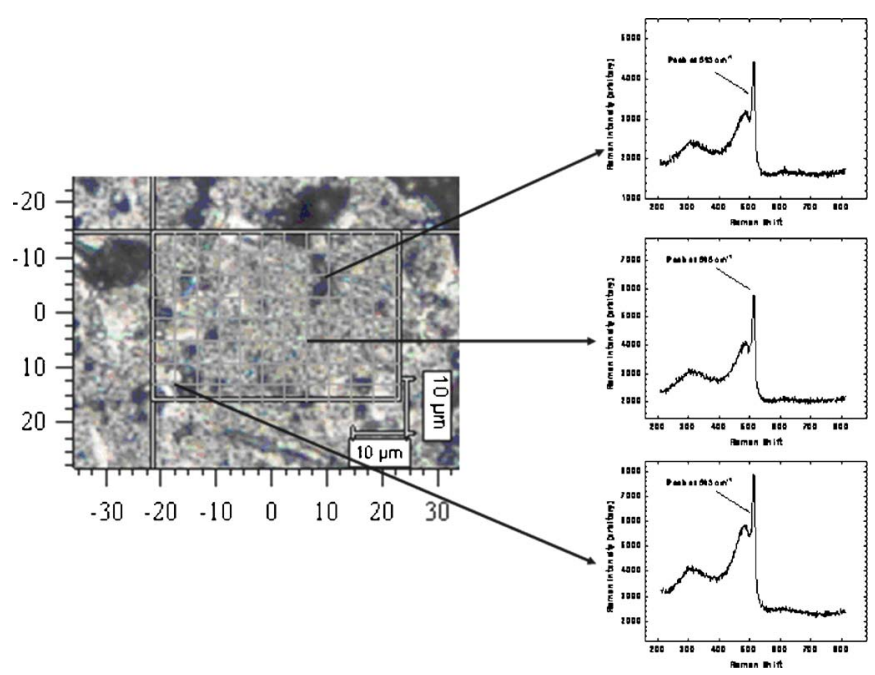

FIG. 4. Raman mapping of the samples prepared by the self-propagation of $\mathrm{Pt} / \mathrm{Al}$ multilayer films. 


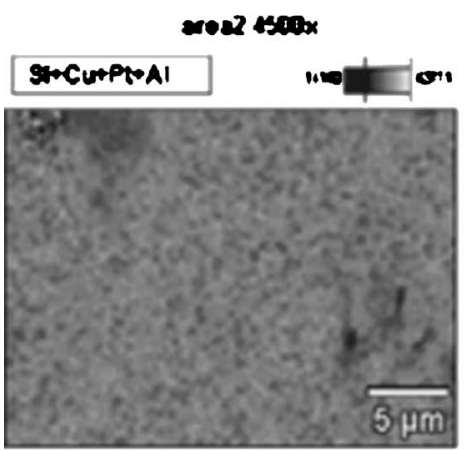

(a)

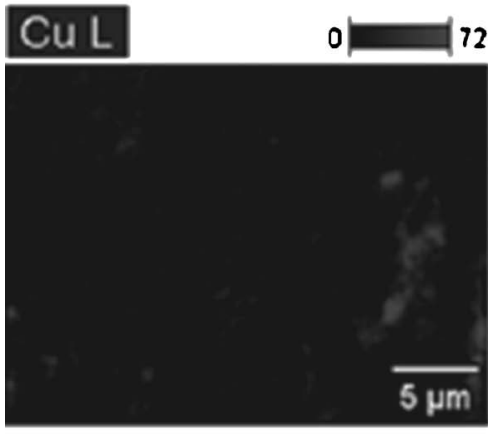

(c)

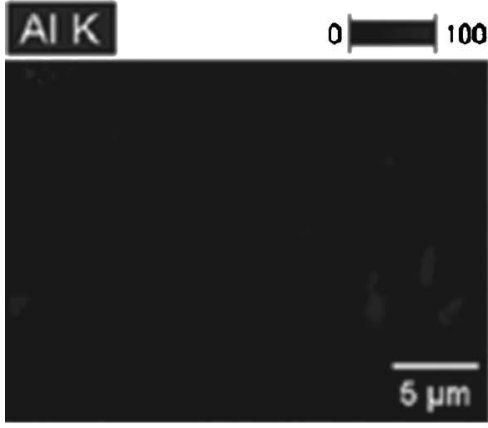

(e)

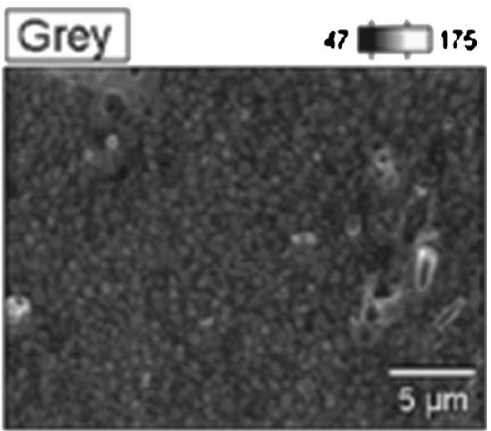

(b)

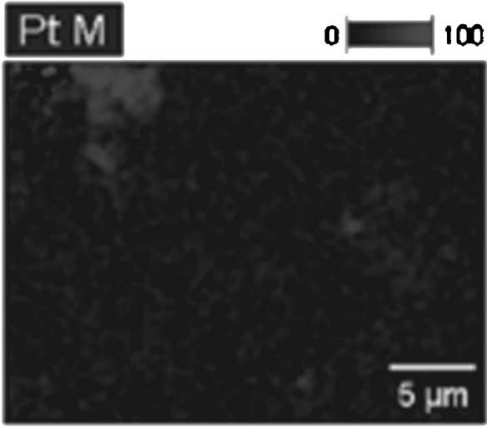

(d)

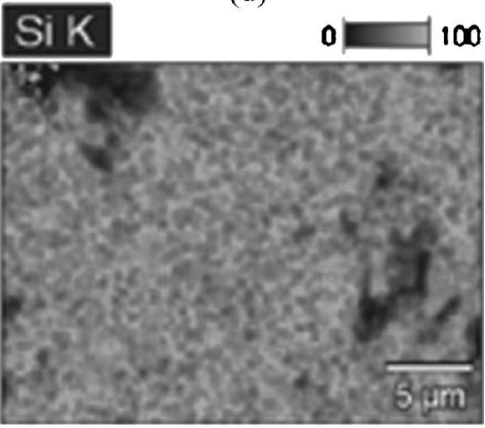

(f)
FIG. 5. EDS mapping of the samples prepared by the self-propagation of $\mathrm{Pt} / \mathrm{Al}$ multilayer films confirms that the poly-Si formed as a whole layer.
$a$-Si did not react with the thermites during self-propagation.

The fast propagating chemical reaction in thermites may generate shock waves and influence the crystallization process. To understand the mechanism of the crystallization, samples were also prepared by introducing a thin aluminum layer of $45 \mathrm{~nm}$ between the $a$-Si and thermite. The metal layer may reduce the diffusion of thermites into $a$-Si during reaction and may also control the crystallization depth. Raman mapping was also performed on the sample and a maximum of $43 \%$ crystalline volume fraction was achieved due to the partial heat loss to the metal layer compared to $100 \%$ crystalline volume fraction for the sample without an $\mathrm{Al}$ layer. This verifies that the crystallization was mostly due to the heating effect. Further experiments are needed to understand the effect of shock waves on crystallization.

As such, the crystallized sample is not uniformly crystalline; rather, it has microcrystals embedded in $a$-Si. The samples prepared by introducing the $\mathrm{Pt} / \mathrm{Al}$ multilayer structure between $a$-Si and $\mathrm{CuO} / \mathrm{Al}$ thermites were ignited and characterized. Our experiments have shown that the selfpropagating reaction with $\mathrm{Pt} / \mathrm{Al}$ multilayer structure cannot be sustained by the usual way of heating a Pt heater with a voltage source. $\mathrm{CuO} / \mathrm{Al}$ nanoengineered thermites were coated on top of the $\mathrm{Pt} / \mathrm{Al}$ multilayer structure to initiate the uniform reaction in $\mathrm{Pt} / \mathrm{Al}$ thermite using the released heat of $\mathrm{CuO} / \mathrm{Al}$ thermites. Metal/metal thermites usually have slow self-propagating reactions in the range of $1-10 \mathrm{~cm} / \mathrm{s} .{ }^{13}$ The heat losses to the substrates may be the reason why the metal/metal thermite cannot sustain the self-propagating reaction when deposited on the substrates.

After the initiation of the self-propagating reaction, the samples were etched in the $\mathrm{Al}$ etchant $\left[85 \% \mathrm{H}_{3} \mathrm{PO}_{4}, 5 \%\right.$ $\mathrm{HNO}_{3}, 5 \% \mathrm{CH}_{3} \mathrm{COOH}$, and $5 \%$ de-ionized (DI) water heated at $40{ }^{\circ} \mathrm{C}$ ] to remove the residue of the reaction. Raman mapping was performed on the sample, which showed (see Fig. 4) almost uniform crystallization in a $45 \times 35 \mu \mathrm{m}^{2}$ region. The data were measured in $3 \mu \mathrm{m}$ intervals. The crystalline volume fraction for all points in the mapping region was calculated to be in the range of $60 \%-65 \%$ with FWHM of $6 \mathrm{~cm}^{-1}$ at a position of $515 \mathrm{~cm}^{-1}$. Higher peak shift for this sample suggests having higher residual stress. Slow propagation of energetic reaction in intermetallic thermites may result in slow heat transfer to $a-\mathrm{Si}$ and have higher thermal stress.

Figure 5 shows the EDS mapping along with the SEM image. Figure 5(a) corresponds to the combined mapping of 


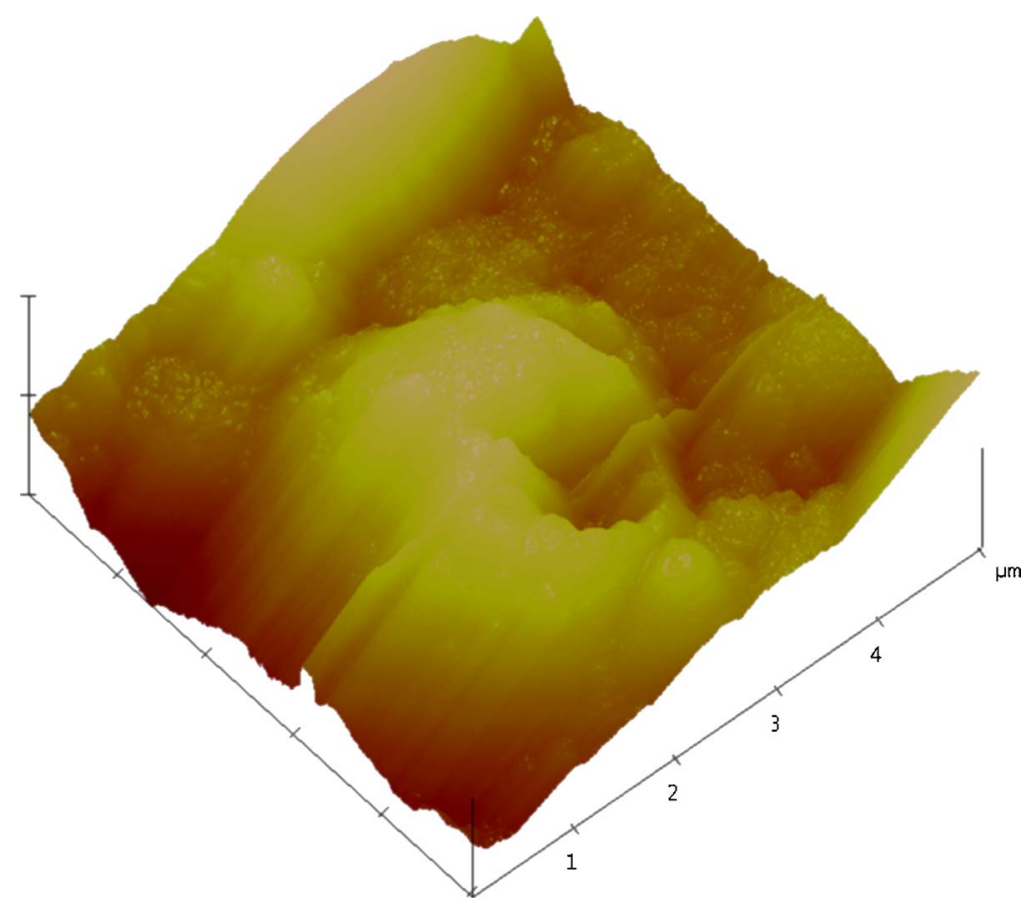

FIG. 6. AFM image of the samples prepared by the self-propagation of $\mathrm{Pt} / \mathrm{Al}$ multilayer films confirms uniform crystallization with grain sizes around $3 \mu \mathrm{m}$.

all four materials, while Fig. 5(b) shows the SEM image of the same region. Figures 5(c), 5(d), 5(e), and 5(f) show mapping of each individual $(\mathrm{Cu}, \mathrm{Pt}, \mathrm{Al}$, and $\mathrm{Si}$, respectively) material. In each individual mapping, a bright region represents the presence of the material, while a dark region represents the absence of the material. In the individual mapping, $\mathrm{Si}$ shows almost all bright regions. $\mathrm{Cu}, \mathrm{Al}$, and $\mathrm{Pt}$ mapping shows the opposite of $\mathrm{Si}$ with almost all dark with a few bright regions. The combined mapping shows a continuous layer of $\mathrm{Si}$ confirming uniform crystallization with small amounts of $\mathrm{Pt}, \mathrm{Al}$, and $\mathrm{Cu}$, which are the residue of the thermite reaction and can be etched with proper etchant. The $\mathrm{Pt} / \mathrm{Al}$ multilayer structure significantly reduced the $\mathrm{CuO} / \mathrm{Al}$ reaction with $\mathrm{Si}$. In this case $\mathrm{CuO} / \mathrm{Al}$ functioned as an ignitor for $\mathrm{Pt} / \mathrm{Al}$ and $a-\mathrm{Si}$ absorbed the released heat from the $\mathrm{Pt} / \mathrm{Al}$ thermite. The $\mathrm{Pt} / \mathrm{Al}$ multilayer structure uniformly released the heat from thermite reaction which caused the uniform crystallization of $a-\mathrm{Si}$.

Morphological properties of the prepared films have been investigated by AFM. The measurement was performed with a Nanoscope IIIa (Veeco Instruments, Inc.) operating in the noncontact or tapping mode. Commercial ultrasharp, rectangular silicon cantilevers made by Micromasch were used having a nominal spring constant of $\sim 0.35-0.70 \mathrm{~N} / \mathrm{m}$. Figure 6 shows the AFM image of the sample for a 5 $\times 5 \mu \mathrm{m}^{2}$ region. The image shows uniform crystallization with the grain size of about $3 \mu \mathrm{m}$.

Conductivity measurements on both samples (controlled and processed by $\mathrm{Pt} / \mathrm{Al}$ multilayer structure) were performed by depositing $\mathrm{Al}$ contacts using the transmission line method (TLM). ${ }^{14}$ The dark conductivity and photoconductivy of the films before and after the combustion process with the $\mathrm{Pt} / \mathrm{Al}$ multilayer structure were measured using the microscope light source $20 \mathrm{~W}$, halogen bulb). The results were 3.8 $\times 10^{-9} \Omega^{-1} \mathrm{~cm}^{-1}$ (dark) and $1.5 \times 10^{-5} \Omega^{-1} \mathrm{~cm}^{-1}$ (light), and $\sim 1 \Omega^{-1} \mathrm{~cm}^{-1}$ (dark) and $\sim 1 \Omega^{-1} \mathrm{~cm}^{-1}$ (light), respectively.
This increase in the dark conductivity after the processing of the sample may be due to the combined effect of doping and poly-Si layer formation. ${ }^{15}$ This doping may be due to the metal diffusion in $a$-Si. ${ }^{14}$ Doping type and doping concentration calculations will be performed in our future work.

This work constitutes our initial study of the crystallization of $a$-Si by self-propagation of thermites. Raman spectroscopy confirmed the crystallization of $a$-Si and the generated Raman maps show uniform formation of polycrystalline Si. In the Pt/Al multilayer case, SEM and EDS analyses confirmed the formation of poly-Si as a whole layer. AFM analysis confirmed the grain size to be around $3 \mu \mathrm{m}$. In conclusion, combining Raman spectra, SEM images, and EDS and AFM analyses gives rich information about the crystallization of $a$-Si by the ignition of the nanoengineered thermites.

The authors acknowledge Dr. Hameed A. Naseem, Professor of the University of Arkansas, for providing the $a$-Si samples. The authors also acknowledge the NSF NIRT (Grant No. 1316-1898-01) for funding this project.

${ }^{1}$ J. H. Werner, R. Bergmann, and R. Brendel, in Advances in Solid State Physics, edited by R. Helbig (Viewag, Braunschweig, 1995), Vol. 34, p. 115

${ }^{2}$ J. F. A. Nijs, Advanced Silicon and Semiconducting Silicon-Alloy Based Materials and Devices (Institute of Physics Publishing, Bristol, 1994).

${ }^{3}$ S. Sriraman, S. Agarwal, E. S. Aydil, and D. Maroudas, Nature (London) 418, 62 (2002).

${ }^{4}$ O. Nast and S. R. Wenham, J. Appl. Phys. 88, 124 (2000).

${ }^{5}$ G. Gotz, Appl. Phys. A: Solids Surf. A40, 29 (1986).

${ }^{6}$ D. J. W. Mous, P. A. Stolk, W. C. Sinke, C. W. T. Bulle-Lieuwma, and D. E. W. Vandenhoudt, Appl. Phys. Lett. 55, 1097 (1989).

${ }^{7}$ S. Gangopadhyay, R. V. Shende, S. Bhattacharya, Y. Gao, and S. Apperson (unpublished).

${ }^{8}$ S. Apperson et al., Mater. Res. Soc. Symp. Proc. 896, H01-06 (2005).

${ }^{9}$ R. Shende et al., Mater. Res. Soc. Symp. Proc. 896, H01-05 (2005).

${ }^{10} \mathrm{~S}$. H. Fischer and M. C. Grubelich, Proceedings of the 24th International Pyrotechnics Seminar, Monterey, CA, 1998 (unpublished).

${ }^{11}$ J.M. Owens, D. Han, B. Yan, J. Yang, K. Lord, and S. Guha, Mater. Res. 
Soc. Symp. Proc. 762, A4.5.1 (2003).

${ }^{12}$ K. Kitahara, R. Yamazaki, T. Kurosawa, K. Nakajima, and A. Moritani, Jpn. J. Appl. Phys., Part 1 41, 5055 (2002).

${ }^{13}$ E. M. Hunt and M. L. Pantoya, J. Appl. Phys. 98, 034909 (2005).
${ }^{14}$ M. S. Haque, H. A. Naseem, and W. D. Brown, J. Appl. Phys. 79, 7529 (1996).

${ }^{15}$ R. Morimoto, C. Yokomori, A. Kikkawa, A. Izumi, and H. Matsumura, Thin Solid Films 430, 230 (2003). 